\title{
Некоторые аспекты цифровой трансформации в развитии экономической теории воспроизводства
}

\section{Леонид Сергеев}

Калининградский государственный технический университет, г. Калининград, Россия

\author{
Информация о статье \\ Поступила в редакциюю: \\ 17.10.2020 \\ Принята \\ к опубликованию: \\ 30.11.2020 \\ УДК 004 \\ JEL A10, D60, L86
}

\begin{abstract}
Ключевые слова:
воспроизводство общественного продукта, цифровые платформы, цифровая стоимость, информационные технологии, добавленная стоимость, цифровые пропорции
\end{abstract}

\footnotetext{
Keywords:

the reproduction of the social product. Digital platform. Digital cost. Information technologies, added value, digital proportions
}

\begin{abstract}
Аннотация
Рассматриваются особенности воспроизводственных отношений в условиях ијифровизации экономического развития общества и перехода от одной экономической формации развития общества к другой, что получает новую технологическую платформу регулирования взаимодействия производительных сил и производственных отношений. Обосновывается понятие цифровой стоимости товара, анализируется смещуение равновесной цень (стоимости) спроса и предложения товара в процессе использования сетевых платформ. Подчеркивается, что качество и глубина ичифровой трансформации технологических прочессов создаваемой стоимости товара позволяют в условиях рынка быстрее отождествлять меновую $и$ потребительную стоимости товара, ускорять воспроизводственные процессы. Обобщается сфера обращения, которая приобретает новые черты, вызванные возможностями циифровизащии процессов куплипродажи товаров в обществе и постепенным преобразованием денежного обращения. Утверждается, что ичирровые модели и средства связи в первичных иерархических секторах экономической системы общества, начеленные на потребности конкретного человека, будут превалирующими элементами общественного воспроизводства. Натуральностоимостные пропоричи создания совокупного продукта общества получают новые формы, которые можно охарактеризовать как ичифровое воспроизводство.
\end{abstract}

Some Aspects of Digital Transformation in the Economic Theory of the Reproduction Development

Leonid Sergeev

\section{Abstract}

The features of the reproductive relations under the conditions of digitalization of the society economic development, the transition from one economic formation of a society development to another are considered, that gets a new technological platform for regulating the interaction of productive forces and industrial relations. The paper substantiates the concept of the goods digital value, analyzes the shift in the equilibrium price (cost) of goods supply and demand in the process of the network platforms applying. It is emphasized that the quality and depth of digital transformation of the goods created value technological processes allow to identify the goods exchange-value and the use-value faster under the market conditions, and 
to accelerate reproduction processes. The sphere of circulation, which acquires new features caused by the possibilities of the goods purchasing and selling processes digitalization in the society and the gradual transformation of currency circulation is generalized. It is stated that digital models and means of communication in the primary hierarchical sectors of the society economic system, aimed at the needs of a particular person, will be the prevailing elements of the social reproduction. The natural - value proportions of the society's cumulative product creation get new forms that can be described as digital reproduction.

\section{Основные положения}

- Закон неуклонного роста и повышения производительности труда как фундаментальный основополагающий постулат перехода от одной экономической формации развития общества к другой получает новую цифровую технологическую платформу регулирования взаимодействия производительных сил и производственных отношений;

- эволюционные преобразования технологий во всех сферах жизнедеятельности общества (производство, распределение, обмен и потребление совокупного общественного продукта) дают новую форму и содержание для всех процессов воспроизводства и социальной жизни общества;

- стоимость как экономическая категория в цифровой экономике получает новое экономическое содержание, которое может быть выражено как «информационная теория стоимости»;

- в условиях цифровизации экономических процессов в обществе происходит смещение равновесной цены (стоимости) спроса и предложения товара, которое может быть представлено как движение точки равновесия с одновременным снижением стоимости и ростом объема выпуска товара.

\section{Fundamentals}

- the law of steady growth and increase in labor productivity as a fundamental postulate of the transition from one economic formation of the society development to another gets a new digital technological platform for regulating the interaction of productive forces and industrial relations;

- the evolutionary transformations of technologies in all spheres of the society vital functioning (production, distribution, exchange and consumption of the aggregate social product) provide a new form and content for all processes of reproduction and social life of society;

- value as an economic category in the digital economy acquires a new economic content, which may be expressed as «information theory of value»;

- with the digitalization of economic processes in the society, there is a shift in the equilibrium price (value) of the goods demand and supply, which can be represented as the equilibrium point movement with a simultaneous decrease in value and increase in the volume of goods output.

\section{Введение}

Воспроизводственные процессы в условиях цифровизации экономического развития общества и перехода от одной экономической формации развития к другой получают новую технологическую платформу регулирования взаимодействия производительных сил и производственных отношений. Цифровые платформы требуют уточнения основных положений содержания и сущности воспроизводственных отношений на базе новых технологических сетевых систем производства, распределения, обмена и потребления совокупного общественного продукта. Целью статьи является обобщение некоторых вопросов развития теоретических положений воспроизводственных отношений в обществе на базе использования цифровых технологий.

Используется метод научной абстракции. Применяется анализ и синтез, а также системный подход и логический метод при исследовании экономических явлений.

\section{Результаты}

В научно-прикладной действительности можно часто услышать вопрос: «Чем и как оценить реалии экономической жизни»? Многочисленные социально-экономические показатели (внутренний валовый продукт на жителя, производительность труда, продолжительность жизни населения, обеспеченность условиями жизни и другие) являются лишь вершиной айсберга, который зиждется на громаднейшей базе цифровых (численных) данных. Численные параметры 
социально-экономических показателей - это конкретные традиционно статистические и безгранично многочисленные (большие данные) цифры, которые принимают новое количественное и качественное значение на современном этапе развития производительных сил и производственных отношений в обществе.

Экономика как научно-прикладное понятие и теоретическая дисциплина в условиях расширения и углубления использования информационно технологических коммуникационных систем в жизнедеятельности общества требует нового осмысления фундаментальных положений теории общественного воспроизводства, базирующегося на цифровой основе. Действие объективных экономических законов в обществе начинает проявлять новые грани и особенности в условиях стремительного развития сетевого цифрового технологического взаимодействия во всех сферах жизнедеятельности общества.

Сетевые цифровые каналы связи, информационно-коммуникационные платформы позволяют практически мгновенно реагировать на различные геополитические решения в мире или в отдельных регионах и на последствия этих решений для экономических систем общества (изменение биржевых индексов ценных бумаг, изменение мировых цен на энергоресурсы, рост или падение курсов национальных валют и другие перемены). Качественное преобразование цифрового взаимодействия по сравнению с аналоговыми связями в постиндустриальном несетевом аналоговом мире позволяют по-новому взглянуть на традиционное проявление и действие всех экономических законов. Отдельные законы теряют былую силу, утрачивают свое действие в эпоху цифровой трансформации экономики. Фундаментальные экономические законы усиливают свое проявление в жизнедеятельности общества и приобретают новые цифровые оттенки, которые требуют теоретического обоснования и научно-прикладного рассмотрения.

Закон неуклонного роста и повышения производительности труда как фундаментальный основополагающий постулат перехода от одной экономической формации развития общества к другой получает новую технологическую платформу регулирования взаимодействия производительных сил и производственных отношений. Взаимодействие этих фундаментальных положений экономической теории получает новое качественное содержание на базе новых цифровых технологий. Цифровизация производства, стремительное преобразование производственных процессов с использованием соответствующих платформ информационно-коммуникационных технологий (далее - ИКТ) требует реформирования системы производственных отношений (организация хозяйственной деятельности, управление и регулирование производства, стимулирование, peформирование форм собственности и другие формы экономических отношений). Эти формы стремительно приобретают новые качественные технологические основы взаимодействия во всех формах и сферах регулирования как хозяйственной деятельности, так и общественно-социальных отношений.

Яркий пример цифровых возможностей революционных преобразований в общественной жизни - это социальные сети интернета, которые могут поднять волну массовых движений для решения различных проблем развития общества. Эти же сети в экономическом развитии могут ориентировать общество на критику или поддержку отдельных элементов воспроизводственных пропорций, устанавливаемых органами власти. Органам власти следует прислушиваться к массовым сетевым высказываниям населения в отношении направлений социально- экономического развития общества, что является сейчас настоятельной необходимостью в силу практически мгновенной передачи информации по социальным сетям и возможным негативным последствиям для общества в силу отсутствия согласования интересов органов власти и населения. 
Постоянное философское противоречие в экономической теории системы производительных сил и производственных отношений разрешается путем цифровых преобразований форм и процессов производственных и социальных сфер жизнедеятельности в обществе. Цифровые платформы (робототехника, искусственный интеллект, виртуальная реальность, промышленный интернет, интернет вещей и др.) способствуют поступательному замещению живого труда на производстве и в обращении овеществленным трудом. При этом общие затраты как живого, так и овеществленного труда на производство продукции сокращаются, что говорит о реализации требования действия объективного экономического закона неуклонного повышения производительности труда при переходе от одной формации экономического развития к другой последующей (более развитой) формации.

В статье [1] отмечается, что общественное развитие находится в стадии перехода от аналогово-рыночной к информационно-сетевой системе организации производства, к информационно-коммуникационной универсализации и унификации, которую можно считать формой огромного информационносетевого, био-квантового общества. В настоящих условиях началась новая технолого-информационная нейронно создаваемая цифровая эпоха, которая способствует созданию интегрированной макросети «Нейронет». Технологическим ядром данной сети служат глобальные, сетевые, гибридные, компьютерные интерфейсы. Фундамент промышленной траектории движения цифровизации составляет развитие сетей связи на базе $5 \mathrm{G}$, цифрофикация промышленного производства, промышленный интернет, роботизация, 3-D проектирование продукции и печать. Отмечается, что цифровизация промышленного производства рассматривается как основополагающий фактор увеличения роста производительности мировой промышленной деятельности. Новые технологические и технические решения развития производительных сил требуют уточнения теоретических положений воспроизводственных отношений в обществе.

Цифровые данные, в информационной теории и информационных системах, являются дискретными, прерывистыми представлениями информации или работ, как противопоставлено непрерывным, или аналоговым сигналам, которые ведут себя непрерывным способом или представляют информацию, используя непрерывную функцию [2]. Поэтому непрерывность взаимодействия громадного многообразия цифровых платформ в системе воспроизводственных отношений является важным фактором нового качественного обобщения теоретических положений экономической науки. При этом здесь важна соответствующая научная методология анализа и теоретического обоснования содержания сквозной цифровизации комплекса всех процессов и элементов формирования стоимости совокупного общественного продукта в процессе его постоянного расширенного воспроизводства.

Эволюционные преобразования технологий во всех сферах жизнедеятельности общества (производство, распределение, обмен и потребление совокупного общественного продукта) дают новую форму и содержание для всех процессов воспроизводства и социальной жизни общества, в которых ведущую роль в повышении эффективности деятельности начинают играть цифровые агрегаторы. Цифровые технологии видоизменяют традиционный экономический уклад и структуру натурально стоимостных воспроизводственных пропорций в обществе. Кругооборот натурально стоимостных процессов ускоряется и модернизируется под воздействием новых ИКТ. Модернизация касается всех сторон используемых факторов производства, всей воспроизводственной деятельности общественного продукта и многообразной социальной жизни общества.

Цифровые технологические платформы становятся важнейшей составляющей частью орудий труда на производстве, в сфере обращения, обмена и потреб- 
лении совокупного общественного продукта. Эта часть цифровизации процессов приобретает все большее значение в структуре общественно необходимых затрат на производство товаров, работ и услуг в обществе. Меняется органическое строение создаваемого общественного продукта в условиях цифрового производства в направлении увеличении доли овеществленного труда в общих затратах труда на производство товаров, работ и услуг. Можно говорить о формировании нового экономического уклада в системе воспроизводственных отношений общества.

Данный новый экономический уклад переводит систему производственных и общественных отношений на цифровые форматы социального и хозяйственного взаимодействия, которые преобразуют традиционные аналоговые воспроизводственные процессы и общечеловеческие коммуникации в обществе. На первое место выходит технологический уклад, который ускоряет экономическое развитие общества путем коренного реформирования систем и процессов воспроизводства общественного продукта.

Стоимость как экономическая категория в цифровой экономике получает новое экономическое содержание, которое может быть выражено как «информационная теория стоимости» [3]. Информационная теория стоимости является новым качественным содержанием данной категории, где традиционно данная категория понималась как меновая стоимость или потребительная стоимость. В работе [3] отмечено, что информационная теория стоимости - это такая концепция, которая предусматривает, что по мере общественного развития информация, знания и способы их практического использования в хозяйственной деятельности постепенно заменяют труд как носителя прибавочной стоимости общественного продукта. Прибавочная стоимость получает постоянное циклическое дополнительное приращение в процессе постоянного воспроизводства общественного продукта. Трудовая теория стоимости как базис воспроизводственных отношений насыщается постоянно совершенствующимся цифровым содержанием соответствующих технологических процессов и получает новое экономическое звучание.

Это звучание является объективным требованием действия экономических законов ускорения (экономии общественного времени) и поднятия на новый уровень многочисленных систем общественного и корпоративного секторов экономики в условиях развития воспроизводственных процессов в обществе. В системе комплекса факторов производства распределения, обмена и потребления усиливается воздействие и получает повышенное влияние такая технологическая коммуникация, которая зиждется на многочисленных цифровых платформах и огромных цифровых базах данных непрерывно осуществляемых воспроизводственных и социальных процессов в обществе.

Новые цифровые технологии позволяют значительно глубже проникнуть в содержательные воспроизводственные процессы формирования стоимости как экономической категории. Если говорить о стоимости потребленных средств производства при формировании товара, то используемые оцифрованные орудия труда и предметы труда в процессе трудовой деятельности - это вся детальнейшая сквозная на соответствующих платформах предыстория и итоги формирования затрат предыдущего (овеществленного) труда. Эта предыстория включает в цифровом формате все многочисленные этапы создания в стоимостной форме орудий и предметов труда, используемых для производства общественного продукта. Аналогично, оцифрованная стоимость необходимого продукта - это вся детальная сквозная стоимостная оценка формирования затрат и результирующий итог оплаты живого труда в процессе воспроизводственной деятельности. Оцифрованную стоимость прибавочного продукта можно представить как ре- 
зультат рыночной стоимостной оценки товара в процессе обмена (куплипродажи на соответствующих торговых сетевых площадках).

На наш взгляд, наряду с понятиями потребительной и меновой стоимости товара стоимостная категория получает новое содержание, которое можно охарактеризовать как цифрровая стоимость товара. Эта стоимость определяется такими новыми содержательными характеристиками, как ее сравнительно с другими факторами воспроизводства новое качество всеобщности (универсальности) и более совершенные возможности регулирования с ее помощью общественного воспроизводства. Эти возможности значительно превышают традиционные организационно-управленческие ресурсы и формы управления общественного воспроизводства. Информационные технологии дают новые возможности анализа и планирования расширенного воспроизводства в обществе.

Цифровая стоимость товара - это обезличенная форма конкретного экономического блага (актива), которая имеет способность быть оцифрованной на электронных носителях информации и функционировать как стоимостной воспроизводственный агрегат в условиях развития сетевой экономики общества. Этот универсальный агрегат обладает такими свойствами, которые существенно повышают эффективность всех сторон воспроизводственных отношений в обществе - ускорение кругооборота создаваемой стоимости общественного продукта, рост производительности совокупного труда, рост прибавочного продукта, сокращение затрат труда в процессе производства. Данные преобразования базируются на развитии и использовании таких основных сквозных цифровых технологий во всех сферах воспроизводства, как:

- огромнейшие массивы цифровых баз данных;

- нейронные технологии и искусственный интеллектуальные системы;

- системы распределенного реестра;

-квантовые технологические системы;

- мобильные сети пятого поколения;

-виртуальная реальность.

Цифровая форма стоимости потребленных средств производства (зданий, оборудования, сырья, расходных материалов, комплектующих и др.) складывается из соответствующих составляющих на сетевых платформах учета поступления (покупки) и использования (списания) основных фондов, оборотных средств и других активов. Непременным орудием труда начинают все шире выступать различные цифровые платформы и сетевые ресурсы прежде всего в производстве совокупного продукта. Стоимость необходимого и прибавочного продукта (рабочей силы и прибыли) также получает новое качественное технологическое содержание, которое заключается в формировании соответствующих затрат живого труда в условиях цифровизации бизнес-процессов, организации производства и продажи продукции в новых сетевых условиях.

Цифровые платформы, сервисы и различные сетевые приложения являются, на наш взгляд, экономическими элементами двойного назначения для воспроизводства общественного продукта. С одной стороны, они составляют часть средств производства (специфические орудия труда), с другой стороны, они представляют возможность их обобщения как элемента системы производственных отношений. При разработке ИКТ, компьютерных программ и различных сервисов, приложений они являются предметом труда. Как элемент производственных отношений, это процессы государственного и корпоративного регулирования на цифровых платформах, которые обеспечивают для экономических агентов планирование, взаимоотношение с бюджетом, реализацию нормативно- 
законодательных форм и другие составляющие экономических форм взаимосвязей государства, предприятий, работников и иных экономических субъектов.

Некоторые исследователи [4] отмечают, что процессы цифровизации (в применительно к человеку, предприятию, отрасли, государству ) - это трансформация к созданию добавленной стоимости путем расширения использования все больше независимых от непосредственного участия человека хозяйственных и воспроизводственных процессов, обладающих возможностью адаптивности (самооптимизации). Данное свойство базируется на использовании экономико-математических моделей (которые можно считать цифровыми двойниками), которые воспроизводят взаимные связи параметров этих процессов, с преимущественно непосредственно прямым использованием огромной базы первичных цифровых данных в местах их появления отсчитывающих приборов и датчиков IоT, что способствует достижению высокого качества огромной базы цифровых данных (актуальность, релевантность, точность и полнота). Постоянное воспроизводство добавленной стоимости (валового внутреннего продукта), кругооборот стоимостных и натуральных эквивалентов товарно-денежных ресурсов на принципиально новых технологических средствах связи, системах цифрового взаимодействия позволяет существенно повышать эффективность товарообменных и производственных процессов в обществе.

В настоящий момент получили определенное применение и сответствующую базу для дальнейшего научно-прикладного развития цифровые платформы в различных сферах жизнедеятельности общества (здравоохранение, транспорт, государственное управление, образование, медицина, добыча полезных ископаемых, торговля, обеспечение безопасности и др. [5, 6, 7]). В стране приняты и реализуются стратегические документы по развитию цифровой экономики $[8,9]$. Но, на наш взгляд, имеется настоятельная необходимость теоретического обоснования и прикладного развития не только микроэкономического отраслевого цифрового развития, но и макроэкономического воспроизводственного обобщения цифровой трансформации в обществе. В повестку дня следует включать разработку цифровых воспроизводственных моделей развития общества, так как сетевая трансформация требует использования соответствующих новых платформ для управления общественными пропорциями развития.

Всеобщность характеризуется разнообразными, но базовыми и качественно едиными цифровыми платформами, а также сетевыми взаимосвязанными и информационно-коммуникационными технологическими системами. Постепенно деньги как всеобщий эквивалент стоимости замещаются и в некоторых случаях дополняются цифровыми стоимостными агрегатами. Противоречие между развитием производительных сил и состоянием производственных отношений в обществе на настоящем этапе разрешается с помощью углубления и стремительного развития использования цифровых технологий. При этом цифровые технологии становятся своеобразным драйвером (локомотивом) развития общества, который приводит к сокращению общественно - необходимых затрат труда на производство товаров, работ и услуг.

Всеобщий эквивалент стоимости, приобретающий форму цифровой стоимости, становится таким фактором производства, распределения, обмена и потребления общественного продукта, который имеет всеобъемлющую информационно-технологическую природу образования, созданную на новых глобальных, сетевых, гибридных, и других компьютерных интерфейсах. Данные технологические системы позволяют по-новому подходить к построению государственной системы организации управления. Сейчас в стране наблюдается определенное несовершенство и недостаточная конкурентоспособность системы госу- 
дарственного управления. Для обеспечения требуемой системы государственного управления России в долгосрочной перспективе должна быть создана новая система построения системы регулирования, которая станет передовой информационно-коммуникационной, технологической, нормативной и культурной основой будущего развития. Роль такой основы сможет сыграть «Государство-какПлатформа» $[10,11]$. Речь идет о необходимости коренного изменения процессов организации государственного управления, в основе которого должны лежать цифровые платформы экономического регулирования воспроизводственной деятельности и оперативного управления.

Цифровая стоимость товара обладает такими технологическими свойствами, которые вносят в понятия меновой и потребительной стоимости новые оттенки в процессы воспроизводства совокупного общественного продукта. Цифровые платформы позволяют генерировать как новую, так и прошлую информацию о структурных составляющих живого и овеществленного труда, воплощенного в товаре. Оцифрованные орудия и предметы труда, рабочая сила позволяют по-новому взглянуть на меновую и потребительную стоимость товара. Качество и глубина цифровой информации, трансформация технологических процессов создаваемой стоимости товара в процессе производства позволяют в условиях рынка быстрее отождествлять меновую и потребительную стоимости товара, ускорять воспроизводственные процессы.

Меновая стоимость товара - это способность обмениваться товарами, а потребительная стоимость товара - это способность удовлетворять конкретные товарные потребности потребителей. Цифровая стоимость товара является его специфическим свойством, которое открывает новые грани организации товарного воспроизводства. Это свойство - возможность виртуального и необходимость платформенного сетевого обобщения безгранично огромных процессов цифрового обеспечения товарного воспроизводства. Меновая и потребительная стоимость товара в данном случае, как разные грани результатов многочисленных видов труда в обществе, предстают на сетевых платформах в единой комплексной цифровой форме, которая выражает многообразие товаров, работ и услуг и позволяет значительно увеличить скорость товарообмена в процессе общественного воспроизводства.

Стоимость товара с использованием огромной базы данных и цифровых платформ (цифровая стоимость) позволяет высветить новые грани, которые не могут быть обобщены при рассмотрении только меновой или потребительной стоимости товара в традиционной форме. Цифровая трансформация стоимости прослеживается на всех этапах и переделах ее создания и использования как экономического блага в обществе. Трудовая теория стоимости получает новую цифровую технологическую составляющую содержания трудовой деятельности, которая оцифровывается на многочисленных сетевых платформах воспроизводства общественного продукта в сферах производства, распределения, обмена и потребления. Это позволяет расширить трактовку экономических воспроизводственных понятий «относительная стоимость и абсолютная стоимость товара». Все многочисленные трудовые процессы создания и обращения (движения) стоимости товара отражаются в цепочке технологических информационных цифровых платформ производства, распределения, обмена и потребления общественного продукта.

Эта огромнейшая информационно-технологическая база цифровой стоимости способствует детальнейшему отслеживанию всех воспроизводственных процессов в обществе. Традиционные понятия экономической теории «капитал», «инвестиции», «активы (частные, государственные)» получают новое углубленное содержание, обусловленное их формированием на основе огромнейшей базы 
цифровых данных в процессе общественного воспроизводства. Такие макроэкономические категории как совокупный общественный продукт, валовый продукт, необходимый продукт, прибавочный продукт и другие, сформированные как элементы цифровой трансформации общественного воспроизводства, позволят значительно глубже вникать в многочисленные процессы создания и использования национального продукта общества.

Сквозные цифровые процессы моделирования воспроизводства товаров, работ и услуг позволяют практически в автоматизированном режиме обеспечивать оптимизацию процессов производства, распределения, обмена и потребления общественного продукта в стране. Оптимизация может осуществляться по различным параметрам функционирования экономической системы: прибыльности, воздействия на экологию, безопасности жизнедеятельности и другим показателям. При этом все расчетные параметры для обеспечения процессов кругооборота и воспроизводства общественного совокупного продукта должны включать обоснование соответствующих стоимостных агрегатов показателей товаров, работ и услуг. Цифровая стоимость как экономическая категория выступает универсальным измерителем факторов производства - затрат живого и овеществленного труда, а также используемых естественных природных ресурсов в воспроизводственной деятельности.

Необходимо отметить, что процесс «производство - распределение - обмен - потребление» в реальной экономической действительности социальноэкономического развития никогда не прерывается. При этом все четыре фазы воспроизводства существуют одновременно, поскольку ни одну из фаз невозможно остановить или исключить из единой взаимосвязи операций последовательности форм видоизменения стоимости и создания совокупного продукта, чтобы не разорвать весь воспроизводственный процесс. Цифровые технологии позволяют непрерывно как моделировать, так и осуществлять оценку фактической картины состояния всех фаз воспроизводства стоимости практически в реальном времени. Это дает возможность принимать оперативные решения по внесению при необходимости корректировок в процессы государственного регулирования воспроизводства общественного продукта.

Каждая единица стоимости совокупного продукта общества в условиях цифровой экономики имеет свое цифровое значение. Информационная база движения стоимости имеет способность мгновенного учета каждой составляющей ее единицы, обеспечения оперативного движения в условиях общественного воспроизводства. Технологическая база ИКТ позволяет иметь детальнейшую картину формирования стоимости, обобщать ее составляющие, анализировать производственные процессы, которые являются основой создания стоимости товаров, работ и услуг. Все производственные микропроцессы могут быть оцифрованы и проанализированы в стоимостном формате с целью сокращения себестоимости производимой продукции.

Значительно увеличиваются возможности регулирования общественного воспроизводства в условиях цифровой экономики. Принципиально по-новому могут решаться вопросы народнохозяйственного социально-экономического планирования в обществе. Традиционные различные макроэкономические экономикоматематические модели для планирования и управления развития могут принимать новые глубоко эшелонированные цифровые формы, которые будут формироваться не только и не столько на основе прошедших (ретроспективных статистических) параметров развития (как правило сверху системы государственного управления), а на базе прямых информационных цифровых платформенных связей производителей и потребителей товаров, работ и услуг (планирование воспроизводства в обще- 
стве снизу). Цифровые модели и средства связи в первичных иерархических сектоpax экономической системы общества, нацеленные на потребности конкретного человека, будут превалирующими элементами общественного воспроизводства.

Целеустановки воспроизводственного развития общества будут в определенной мере формироваться снизу на основе огромной базы оцифрованных потребностей в товарах, работах и услугах людей. Задачей высших эшелонов власти будет установление рациональных пропорций воспроизводства с учетом оптимального использования общественного продукта для текущего потребления и необходимого накопления совокупного продукта для развития общества. Такая система формирования общественных и производственных запросов необходимых экономических и социальных благ в первичных звеньях экономической системы (чему способствуют различные цифровые платформы) способствует созданию рациональных отношений в процессе производства, распределения, обмена и потребления общественного продукта. При этом усиливаются горизонтальные хозяйственные связи и уменьшается роль вертикальных регулирующих экономических воздействий на воспроизводственные процессы в обществе.

В условиях цифровизации экономических процессов в обществе происходит смещение равновесной цены (стоимости) спроса и предложения товара, которое может быть представлено как движение точки равновесия с одновременным снижением стоимости и ростом объема выпуска товара (рис. 1). Такая трактовка характеризуется результатом повышения производительности совокупного общественного труда в обществе в процессе использования цифровых технологий.

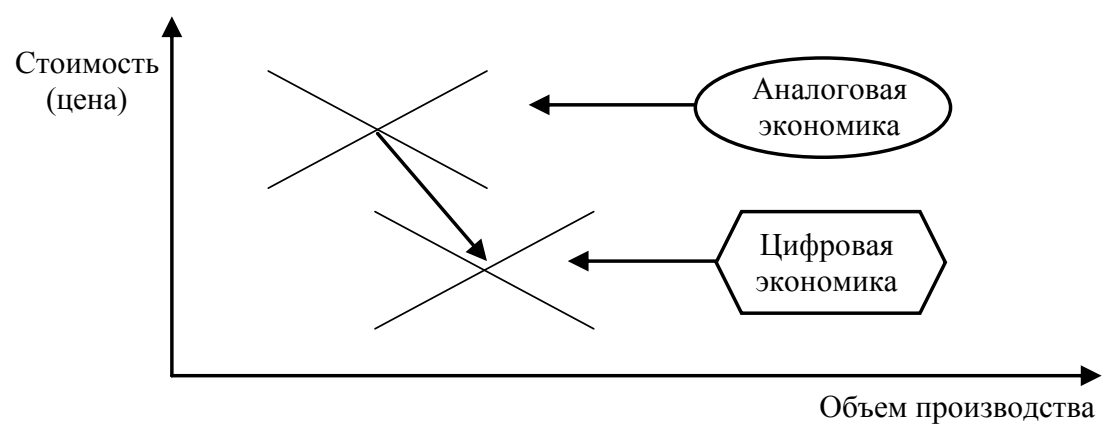

Рис. 1. Изменение рыночного равновесия стоимости (цены) товара в условиях цифровой экономики в сравнении с аналоговой экономикой

Источник: составлено автором

Цифровая стоимость товара на рынке для производителя и потребителя (покупателя) в зависимости от объема выпуска продукции смещается под воздействием прежде всего наличия соответствующих сетевых платформ, способствующих снижению затрат труда для производителя. Относительно производителя товара можно однозначно говорить о сокращении затрат труда на производство при наличии робототехники, программно-цифровых комплексов, сетевых платформ организации и управления, а также других цифровых компонентов производственной деятельности.

Покупатель товара, наделенный значительным количеством комплексов различных цифровых приложений и систем электронных площадок для закупок и обращения товара, также имеет возможность выбора необходимого товара по наиболее низким ценам. Поэтому перекрестие стоимости (цены) спроса и предложения в зависимости от объема производства на рис. 1 смещается вниз и вправо, что говорит об аналогичной динамике изменения равновесной цены спроса и предложения. Таким образом, цифровизация оказывает действенное 
влияние на изменение процессов установления рыночных цен на товары, работы и услуги в условиях развития общества. Это влияние способствует сокращению стоимости товара (рыночной цены продажи) при увеличении его выпуска.

Цифровая трансформация воспроизводственной деятельности позволяет по-новому взглянуть на проявление действия закона стоимости в обществе. Производители цифровых технологических платформ заинтересованы в тиражировании и возможной монополизации своей продукции на рынке. Стоимость технических и технологических элементов баз данных (программных продуктов, интерфейсов, цифровых приложений и других составляющих технологической сетизации в обществе) по мере развития средств связи и сетевых платформ сокращается, а стоимость цифровой информации, которая обрабатывается данными информационно-коммуникационными система увеличивается. Наполненная конкретным цифровым содержанием (числами) технологическая элементная база информационно-коммуникационных систем имеет значительную стоимость (ценность), которая в ряде случаев во много раз превосходит стоимость технических составляющих соответствующих сетевых платформ.

Деньги как всеобщий эквивалент стоимости в цифровую эпоху постепенно замещаются цифровыми аналогами (биткойн, блокчейн, различные криптовалюты, система Яндекс-деньги, система Pay Pal и др.). Закон денежного обращения трактует, что объем денежной массы должен соответствовать потребностям рынка в соответствии со стоимостью произведенных товаров, работ и услуг в обществе. Эта денежная масса должна быть прямо пропорциональна сумме цен на товары, работы, также услуги и обратно пропорциональна скорости обращения денег. Цифровая трактовка закона денежного обращения приводит как к положительному эффекту (увеличение скорости оборота денег, так и к отрицательному результату (снижение возможности процессов государственного регулирования денежного обращения). Появление виртуальных валют - это следствие замещения денег в системе денежного обращения цифровыми аналогами, что меняет в будущем денежно-кредитную систему общества [12].

Цифровые деньги - это еще один существенный элемент новых аспектов воспроизводственных отношений в обществе, который требует отдельного детального изучения и теоретического обоснования целесообразности его использования в процессах создания и кругооборота стоимости общественного продукта. Государственное регулирование воспроизводственных отношений в условиях цифрового аналога стоимости в условиях сокращения действия денежных знаков и системы денежного обращения должно быть детально изучено с точки зрения результативности общественного развития. Цифровая платежная система в условиях наличия виртуальных денег способна ускорить кругооборот воспроизводственных процессов в обществе.

Сфера обращения приобретает новые черты, вызванные возможностями цифровизации процессов купли-продажи товаров в обществе и постепенным преобразованием денежного обращения. Цифровые платформы позволяют осуществлять мгновенные беспроводные кассово-расчетные операции в процессе куплипродажи товаров, работ и услуг. Сферы производства и обращения общественного продукта, базирующиеся на цифровых платформах, позволяют прослеживать всю цепочку создания стоимости товаров, продвижения ее по всем стадиям воспроизводства. Такая детализация способствует более качественному анализу всех воспроизводственных процессов создания и использования общественного продукта для оптимизации натурально-стоимостных пропорций развития общества.

Натурально-стоимостные пропорции создания совокупного продукта общества получают новые формы, которые можно охарактеризовать как цифровое 
воспроизводство. Цифровые модели огромного количества данных многочисленных процессов создания и движения натурально-стоимостных параметров позволяют анализировать цифровую структуру совокупного общественного продукта в различных видах и формах его представления (в динамике, в отраслевом разрезе, в региональном рассмотрении, в различных формах хозяйственной деятельности, в государственном секторе, в корпоративном секторе, в различных группах экономических агентов, в семейных отношениях и в других аспектах рассмотрения). Воспроизводство средств производства, рабочей силы, прибавочной стоимости и других элементов общественного продукта в цифровом формате позволяет осуществлять огромные многоитерационные аналитические экономико-математические расчеты для поиска оптимальных пропорций социально-экономического развития общества.

Как подчеркивает автор статьи [13], государственная цифровая платформа страны, в свою очередь, строится на основе интеграции в единой облачной базе громадных массивов объемов данных цифровой информации первичного учета, технологических параметров и показателей. Эта платформа должна формироваться на основе унифицированной комплексной системы сбора, хранения и анализа первичной учетной, технологической и статистической информации, которую необходимо согласовывать как между собой, так и с единой системой классификаторов, справочников и различных нормативных документов. Первичные системы базы данных должны быть представлены реестрами практически всех материальных, интеллектуальных и человеческих ресурсов страны на основе онтологического экономико-математического моделирования цифровых видов информационных ресурсов. Цифровые платформы дают возможность строить глобальные (на макроуровне) и территориально-отраслевые (смешанные на макроуровне и на микроуровнях) управляющие системы, а также типовые сайты с уменьшением индивидуальных затрат на цифровые экономику в обществе в десятки и сотни раз. Следует отметить, что строящиеся в стране цифровые платформы отражают реализацию ранее высказанных идей советских ученых А.И. Китова и В.М. Глушкова о создании общегосударственной автоматизированной системы сбора и обработки экономической информации для систем учета, планирования и управления народным хозяйством в СССР.

Цифровые возможности позволяют коренным образом видоизменить технологию построения системы национальных счетов (балансовых таблиц), которая характеризует воспроизводимые и невоспроизводимые пропорции стоимостных воспроизводственных параметров (основные фонды, земля, запасы разведанных полезные ископаемые и т.д.), запасы оборотных средств, а также финансовые активы и пассивы, взаимоувязанные с постоянным кругооборотом поступления и списания денежных средств по счетам экономических агентов в обществе. Система национальных счетов представляют собой громадный уровень детализации внутренней политэкономической структуры общества, она являются важнейшей основой осуществления разносторонних расчетов на макроэкономическом уровне. Данная система является эффективным инструментом общегосударственного механизма регулирования многообразных процессов функционирования национальной экономики. Система национальных счетов (далее - СНC) и ее основные показатели на базе цифровых платформ должны быть основной глобальной макроэкономической моделью общественного воспроизводства.

В этой связи интересны положения научной работы ученых РАНХиГС «Перспективы учета и измерения цифровой экономики на основе приложений Системы национальных счетов» [14]. Основная цель исследования заключается в разработке методологических подходов к оценке макроэкономических индикато- 
ров государства в условиях использования цифровых платформ в национальной экономике. В исследовании будет предпринята попытка изучения многочисленных форм реформирования систем координации процессов отношений экономических агентов в рамках современной политэкономической действительности под влиянием углубления результатов цифровизации национальной экономики. Предполагается осуществить предварительный расчет (реакцию) цифровой трансформации на действие различных видов агентов экономической системы. Будет предпринята работа по определению основных параметров эффективности цифровизации и оценка развития ИКТ в условиях экономического роста. Намечается разработка предложений по реализации социально-экономического регулирования в Российской Федерации при дальнейшем углублении процессов цифровизации общества. На взгляд ученых решение данных задач является неотъемлемыми компонентами разработки взвешенных подходов к оценке совокупной факторной производительности, производительности труда и капитала, а также расчета других макроэкономических показателей развития общества.

На наш взгляд, анализ балансовых таблиц системы национальных счетов «затраты - выпуск» (как элемента СНC) с использованием цифровых платформ также позволит на порядок поднять возможности грамотного обобщения воспроизводственных стоимостных пропорций в обществе и делать выводы по принятию эффективных управленческих решений для оптимизации структуры накопления и потребления в обществе. Цифровые платформы позволят на качественно ином повышенном уровне разрабатывать межотраслевые и межтерриториальные балансы развития народнохозяйственного комплекса страны, что будет способствовать грамотному территориальному развитию общества.

Особенности стоимостного подхода в управлении бизнесом в условиях цифровой экономики включают положения формирования цифровой стоимости продукта на микроуровне. Данные подходы [15] включают два основных направления.

1. Модель сети создания стоимости. В отношении данной модели подчеркивается, что важнейшим направлением современной экономики является включение в сферу массового производства различного рода услуг. «В этих условиях модель цепочки создания стоимости, изначально предназначенная для анализа «материалоемкого» бизнеса, утрачивает роль универсального инструмента, обеспечивающего процесс принятия управленческих решений. Для устранения данной проблемы предложена концепция сети создания стоимости, более адекватно отражающая особенности цифрового бизнеса в сфере услуг».

2. Концепция мастерской (цеха) создания стоимости. Данное концептуальное направление используется в основном в случае односторонних рынков, на которых компания взаимодействует с одним типом пользователей или клиентов, решая их специфические проблемы. «Модель отличается использованием интенсивных технологий - сложных комбинаций аппаратных средств, программного обеспечения и знаний, что позволяет относить данный тип бизнеса к категории профессиональных услуг».

Как первое, так и второе направления цифровизации микроэкономического развития требуют дальнейшего изучения природы и сущности экономических положений формирования и использования сетевых приложений и ИКТ в необходимом преобразовании бизнес-процессов в России.

\section{Обсуждение}

Рассмотренные положения затрагивают лишь некоторые актуальные вопросы цифровизации экономики в зеркале воспроизводственных процессов в обществе. Положения могут обсуждаться и дополняться новыми подходами 
оценки содержания цифровизации общественного воспроизводства. Кроме поднятых вопросов и направлений обобщения развития положений трудовой теории стоимости в условиях цифровой трансформации могут быть исследованы также цифровые преобразования общественного развития в русле действия и модернизации содержания других объективных экономических законов. Помимо рассмотренных воспроизводственных подходов К. Маркса к созданию общественного продукта могут обобщаться в условиях цифровой экономики теоретические положения воспроизводства Франсуа Кэне, Т. Мальтуса, Л. Вальраса, В Леонтьева и других экономических школ.

\section{Заключение}

Цифровая трансформация жизнедеятельности общества требует дальнейшего теоретического изучения сущности и содержания экономической теории в условиях сетевых информационно-коммуникационных платформенных преобразований. В настоящий момент практика сетевой трансформации опережает развитие теоретических проблем природы и содержания цифровой экономики.

\section{Список источников / References}

1. Дятлов С.А. Энейро-сетевая экономика: формирование новых сегментов глобального рынка. Современные технологии управления, 2017, №2 (74), cc. 14-35. [Dyatlov S.A. E`nejro-setevaya e`konomika: formirovanie novy`kh segmentov global`nogo ry`nka [Eneuronetwork economy: the formation of new segments of the global market]. Sovremenny'e tekhnologii upravleniya = Modern control technologies, 2017, no. 2 (74), pp. 14-35.]

2. ru.knowledgr.com Available at: http://ru.knowledgr.com/00217724/RiproduzioneDigitale (accessed 21.09.2020)

3. Луценко Е.В. Автоматизированный системно-когнитивный анализ в управлении активными объектами (системная теория информации и ее применение в исследовании экономических, социально-психологических, технологических и организационнотехнических систем): vонография (научное издание). Краснодар, КубГАУ, 2002. 605 c. [Luczenko E.V. Avtomatizirovanny`j sistemno-kognitivny`j analiz v upravlenii aktivny`mi ob`ektami (sistemnaya teoriya informaczii i ee primenenie $\mathrm{v}$ issledovanii e`konomicheskikh, soczial`no-psikhologicheskikh, tekhnologicheskikh i organizaczionnotekhnicheskikh sistem): vonografiya (nauchnoe izdanie) [19. Lutsenko E.V. Automated system-cognitive analysis in the management of active objects (system theory of information and its application in the study of economic, socio-psychological, technological and organizational-technical systems): vonography (scientific publication)]. Krasnodar, KubGAU, 2002. 605 p.].

4. Иванов В.В., Малинецкий Г.Г. Цифровая экономика: мифы, реальность, возможности. Москва, РАН, 2017. 63 с. [Ivanov V.V., Malineczkij G.G. Czifrovaya e`konomika: mify`, real`nost', vozmozhnosti [Digital Economy: Myths, Reality, Opportunities]. Moscow, RAS Publ., 2017, 63 p.]

5. Сергеев Л.И., Юданова А.Л. Цифровая экономика: учебник для вузов. Москва, Юрайт, 2020. 332 c. [Sergeev L.I., Yudanova A.L. Czifrovaya e`konomika: uchebnik dlya vuzov [Digital Economy: a textbook for universities]. Moscow, Yurayt Publ., 2020. 332 p.]

6. Агеев А.И., Аверьянов М.А. Цифровое общество: архитектура, принципы, видение. Экономические стратегии, 2017, №1, сc. 114-124. [Ageev A.I., Aver’yanov M.A. Czifrovoe obshhestvo: arkhitektura, princzipy`, videnie [Digital Society: Architecture, Principles, Vision]. E`konomicheskie strategii = Economic strategies, 2017, no. 1., pp. 114-124.]

7. Что такое цифровая экономика? Тренды, компетенции, измерение: докл. к ХХ Апр. междунар. науч. конф. по проблемам развития экономики и общества, Москва, 9-12 апр. 2019 г. / Г.И. Абдрахманова, К. О. Вишневский, Л. М. Гохберг и др.; науч. ред. Л. М. Гохберг; Нац. исслед. ун-т «Высшая школа экономики». М.: Изд. дом Высшей школы экономики, 2019, сc. 1-82. [What is the digital economy? Trends, competencies, meas- 
urement: reports. to XX Apr. int. scientific. conf. on the problems of economic and social development, Moscow, April 9-12. 2019 / G.I. Abdrakhmanova, K.O. Vishnevsky, L.M. Gokhberg and others; scientific. ed. L. M. Gokhberg; Nat. issled. University Higher School of Economics. Moscow: Ed. House of the Higher School of Economics, 2019, pp. 1-82.]

8. Указ Президента РФ от 9 мая 2017 г. № 203 «О стратегии развития информационного общества в Российской Федерации на 2017-2030 годы». Available at: http://kremlin.ru/acts/bank/41919

9. Распоряжение Правительства РФ от 28 июля 2017 г. № 1632-р «Об утверждении программы цифровой экономики Российской Федерации». Available at: http://base.garant.ru/71734878/

10. Добролюбова Е.И., Южаков В.Н., Ефремов А.А., Клочкова Е.Н., Талапина Э.В., Старцев Я.Ю. Цифровое будущее государственного управления по результатам. Москва, Издательский дом «Дело» РАНХиГС, 2019. 114 с. [Dobrolyubova E.I., Yuzhakov V.N., Efremov A.A., Klochkova E.N., Talapina E`.V., Starcev Ya.Yu. Cifrovoe budushhee gosudarstvennogo upravleniya po rezul tatam [The digital future of public administration by results]. Moscow, Publishing house "Delo" RANEPA, 2019. 114 p.]

11. Государство как платформа. (Кибер)Государство для цифровой экономики. Цифровая трансформация. Москва, 2018. 53 с. [Gosudarstvo kak platforma. (Kiber) Gosudarstvo dlya cifrovoj e`konomiki. Cifrovaya transformaciya [The state as a platform. (Cyber) State for the digital economy. Digital transformation]. Moscow, 2018. 53 p.]

12. Дёрр Д., Ковальски О., Невский, С.И. Цифровизация и денежный порядок. Проблемы и перспективы регулирования рынка криптовалют. Terra Economicus, 2019, №17 (4), cc. 6-22. [Dyorr D., Koval`ski O., Nevskij, S.I. Cifrovizaciya i denezhny`j poryadok. Problemy` i perspektivy` regulirovaniya ry`nka kriptovalyut [Digitalization and monetary order. Problems and prospects of cryptocurrency market regulation]. Terra Economicus, 2019, no. 17 (4), pp. 6-22.] DOI: 10.23683/2073-6606-2019-17-4-6-22.

13. Меденников В.И. Математическая модель формирования цифровых платформ управления экономикой страны. Цифровая экономика, 2019, №5, cс. 25-35. [Medennikov V.I. Matematicheskaya model` formirovaniya cifrovy`x platform upravleniya e`konomikoj strany [Mathematical model of the formation of digital platforms for managing the country's economy]. Cifrovaya e konomika = Digital economy, 2019, no. 5, pp. 25-35.]

14. Перспективы учета и измерения цифровой экономики на основе приложений Системы национальных счетов. Avalaible at: https://ipei.ranepa.ru/ru (accessed 21.09.2020).

15. Харин А.Г. Особенности стоимостного подхода в управлении бизнесом в условиях цифровой экономики. Балтийский экономический журнал, 2020, №2 (30), сс. 116131. [Xarin A.G. Osobennosti stoimostnogo podxoda v upravlenii biznesom v usloviyax cifrovoj e'konomiki [Features of the cost approach in business management in the digital economy]. Baltijskij e`konomicheskij zhurnal = Baltic Economic Journal, 2020, no. 2 (30), pp. 116-131.]

\section{Сведения об авторе / About author}

Сергеев Леонид Иванович, заслуженный экономист Российской Федерации, доктор экономических наук, профессор, заведующий кафедрой экономической теории, Калининградский государственный технический университет. Советский пр., 1, Калининград, Калининградская обл., 236022 Россия, Калининград, Советский проспект, 1.E-mail: doc_sergeevli@mail.ru

Leonid I. Sergeev, Honored Economist of the Russian Federation, Doctor of Economic Sciences, Professor, Head of the Department of Economic Theory, Kaliningrad State Technical University. 1, Sovetskiy pr., Kaliningrad, Russia 236022. E-mail:_doc_sergeevli@mail.ru 